\title{
Review
}

Amandine Pinto and Marc Pocard*

\section{Photodynamic therapy and photothermal therapy for the treatment of peritoneal metastasis: a systematic review}

https://doi.org/10.1515/pap-2018-0124

Received August 24, 2018; accepted November 29, 2018 ; previously published online December 18, 2018

\section{Abstract}

Background: The aim of this review was to analyze preclinical studies and clinical trials evaluating photodynamic therapy (PDT), and photothermal therapy (PTT) in peritoneal metastasis (PM) treatment.

Content: Systematic review according PRISMA guidelines. Electronic searches using PubMed and Clinical Trials.

Summary: A total of 19 preclinical studies analyzing PDT in PM treatment were included. Each new generations of photosensitizers (PS) permitted to improve tumoral targeting. Phase III preclinical studies showed an important tumoral biodistribution (ratio 9.6 vs normal tissue) and significant survival advantage (35.5 vs 52.5 days for cytoreductive surgery vs cytoreductive surgery + PDT, $\mathrm{p}<0.005)$. Height clinical trials showed important side effects (capillary leak syndrome and bowel perforation), mainly explained by low tumor-selectivity of the PS used (first generation mainly).

Peritoneal mesothelioma apparition with carbon nanotubes first limited the development of PTT. But gold nanoparticles, with a good tolerance, permitted a limitation of tumoral growth (reduction of bioluminescence to $37 \% 20$ days after PTT), and survival benefit (35, 32, and 26 days for PTT with cisplatine, PTT alone and laser alone, respectively).

Outlook: Recent improvement in tumor-selectivity and light delivery systems is promising but further development would be necessary before PDT and PTT routinely applied for peritoneal carcinomatosis.

Keywords: photodynamic therapy, photothermal therapy, peritoneal metastasis

\footnotetext{
*Corresponding author: Marc Pocard, Paris Diderot University, Sorbonne Paris Cité, CART, INSERM U965, Paris, France; Surgical Oncologic \& Digestive Unit, Lariboisière Hospital, AP-HP, 2 rue Ambroise Paré, 75475 Paris Cedex 10, France, E-mail: marc.pocard@gmail.com Amandine Pinto, Paris Diderot University, Sorbonne Paris Cité, CART, INSERM U965, Paris, France, E-mail: amandine-pinto@live.fr
}

\section{Introduction}

Peritoneal metastasis (PM) is considered as the terminal stage of malignant disease. The prognosis is poor with a median survival of approximately 5 months without treatment, and 12-24 months with palliative chemotherapy $[1,2]$. The only curative intent treatment option is complete cytoreduction surgery (CRS), consisting to resect all macroscopic disease, following (or not function of PM origin) by hyperthermic intraperitoneal chemotherapy (HIPEC) [2]. The adjuvant application of intraperitoneal (IP) chemotherapy could permit the destruction of residual microscopic disease, which is inevitable after CRS. This treatment presents high mortality rate, about $0-3 \%[3,4]$, and morbidity rates, about $20-60 \%$ [5]. A recent French study (PRODIGE 7) shows that, at 60 days, major morbidity (grade 3-4-5 of the Dindo classification) was higher for patients who received CRS + HIPEC (24.1\%) than patients with CRS only $(13.6 \%)(p=0.03)[6]$. To decrease the morbidity of HIPE, collaborations between physicists, chemists, and surgeons permit to develop new anticancer modalities with a common objective: to improve tumoral selectivity with a more important vectorization. Two therapeutics are analyzed in PM treatment in this review: photodynamic therapy (PDT), and photothermal therapy (PTT).

\section{Photodynamic therapy}

PDT is known for tens of years [7]. After accumulation of a photosensitizer (PS) in cancer cells, more rapidly than nonmalignant tissue, illumination with a light induces cell death. PS is activated with a particular wavelength illumination. Photochemical reaction with oxygen leads to reactive oxygen species (ROS) production. An interaction between ROS and oxygen causes superoxyd oxygen $\mathrm{O}_{2}$. There is an interaction between PS and oxygen ${ }^{3} \mathrm{O}_{2}$ causing oxygen 


\section{Tumoral cell}

Photosensitizer
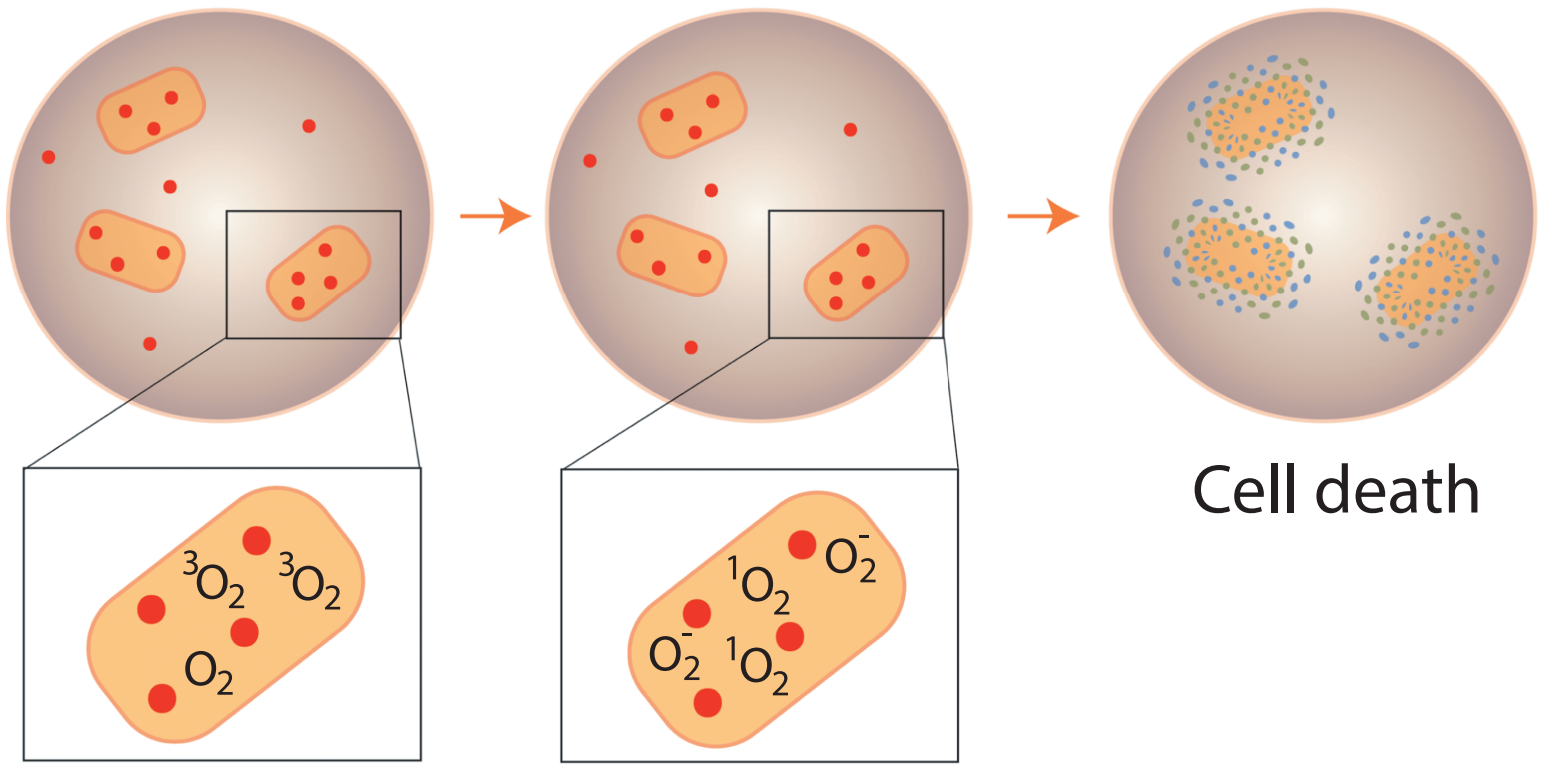

Figure 1: photodynamic therapy: mechanism.

transformation in cytotoxic singlet oxygen ${ }^{1} \mathrm{O}_{2} \cdot \mathrm{O}_{2}$. and ${ }^{1} \mathrm{O}_{2}$ create cell death with two mechanism: direct mechanism (necrosis and apoptosis) and indirect mechanism (microvascular damage [8, 9], and antitumor immune responses [10]) (Figure 1). Many PS were developed, and Photofrin ${ }^{\circ}$ was the first used. In 1972, Diamond and al published, as first, in The Lancet, the effectiveness of PDT in treatment of glioma cells in culture and on subcutaneous glioma on rats [7]. In 1975, Kelly and al published first preclinical results with PDT in the treatment of other type of tumors, namely superficial transitional cell carcinoma of the bladder [11]. The first clinical results were in dermatology [12], especially for the treatment of psoriasis, mycosis fungoides, and skin cancer. The main side effect of this therapy involved the skin, and depended on the doses and continuance of the treatment [13]. Between 1982 and 1984, PDT results for treatment of others cancers were published: tracheobronchial tree cancer [14], lung cancer [15], and esophagus cancer [16]. Tochner was the first, in 1985 [17], to evaluate PDT (with Photofrin ${ }^{\circ}$ ) for PM treatment.

\section{Photothermal therapy}

These last years, we noted a growing interest for therapeutic or diagnostic nanoparticles (NPs) [18]. Some researchers focused on improving the drug delivery systems and on obtaining higher drug concentrations at the site of the disease with a reduction of the toxicity. Kohane [19] showed in 2008 that NPs formulated with lower molecular weight polymers, were safe with lower incidence of peritoneal adhesions. Furthermore, NPs can bypass drug efflux pumps, thus evading multidrug resistance and achieving significantly higher drug accumulation into the tumoral cells compared to IP therapy with the unformulated free drugs [20-22].

More recently, a strategy involving NPs - mediated hyperthermia (PTT), was reported and tested in cancer treatment [23]. PTT appeared like a new antitumoral therapy because of the selective hyperthermia in tumor tissue without toxicity to healthy tissue. After administration and intra tumoral accumulation, plasmonic NPs are illumined with a light of adequate wavelength. It causes the NPs conduction band electrons to undergo synchronized oscillations [24], to convert near-infrared (NIR) light into heat, that ultimately kills cancer cells [25-28]. Three mechanism explain the cell death: cell membrane destruction, tumoral DNA denaturation, and angiogenesis blocking [25-28] (Figure 2). In 2003, first studies described PTT in cancer [27-31].

The aim of the present study was to perform a systematic literature review on photodynamic and photothermal therapies for PM treatment. We analyzed preclinical 


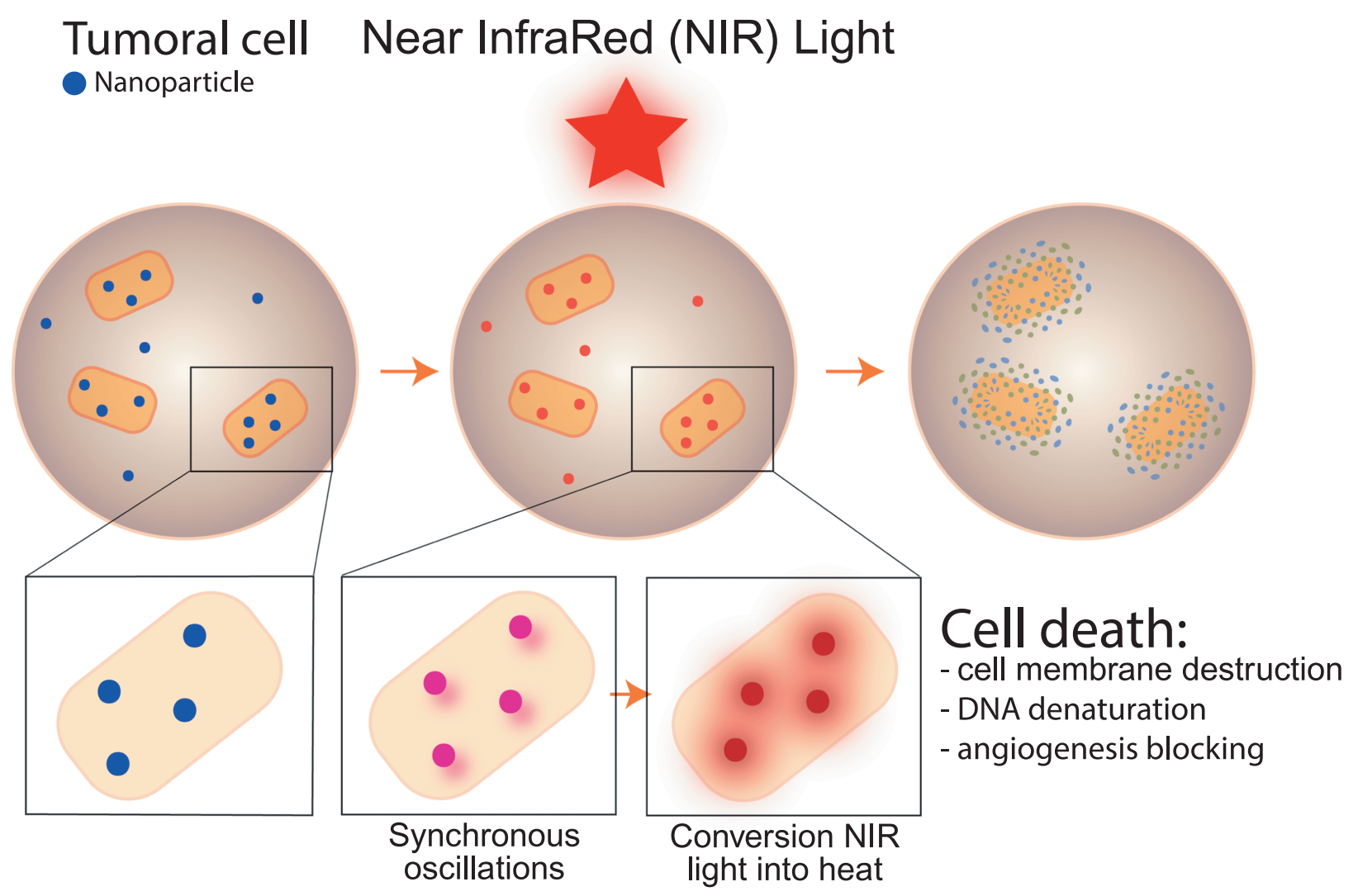

Figure 2: photothermal therapy, mechanism.

and clinical trials function of toxicity (phase I), efficacy and safety (phase II) and survival (phase III).

\section{Materials and methods}

\section{Search strategy}

A systematic review of the literature was conducted using PubMed and Clinical Trials.

On PubMed, combinations of the following terms were used "peritoneal carcinomatosis", "photodynamic therapy", "photothermal therapy", "nanotubes", and "intraperitoneal". Articles were selected by the title first, and by abstract reading (Figure 3). We identified 82 articles with "photodynamic therapy and peritoneal carcinomatosis" terms, but only 3 articles with "photothermal therapy and peritoneal carcinomatosis" terms, 8 with "photothermal therapy and intraperitoneal", and 12 articles by using "nanotubes and peritoneal carcinomatosis".

On Clinical Trials, two trials were proposed with "photodynamic therapy and peritoneal carcinomatosis" terms, but 0 with "photothermal therapy and peritoneal carcinomatosis" or "photothermal therapy and intraperitoneal" or "nanotubes and peritoneal carcinomatosis".

\section{Study inclusion}

\section{Photodynamic therapy}

On PubMed, all studies proposed for "photodynamic therapy and peritoneal carcinomatosis" $(n=82)$ were analyzed. An initial evaluation of the title and abstracts were performed to exclude articles which didn't really evaluate these therapeutic for PM. Many articles were about photodynamic diagnosis and not therapy. We excluded articles about in vitro experimentations. Thirty-one articles were assessed for eligibility: 9 trials, 20 preclinicals studies, and 2 reviews. We analyzed only preclinicals studies and clinical trials. Full text was available for 8 trials and 19 preclinical studies. We included, finally, these 27 articles.

On clinical trials, only 1 of the 2 trials proposed was really about the PDT (NCT02840331). 
Initial Search « photodynamic therapy and peritoneal carcinomatosis $», n=82$

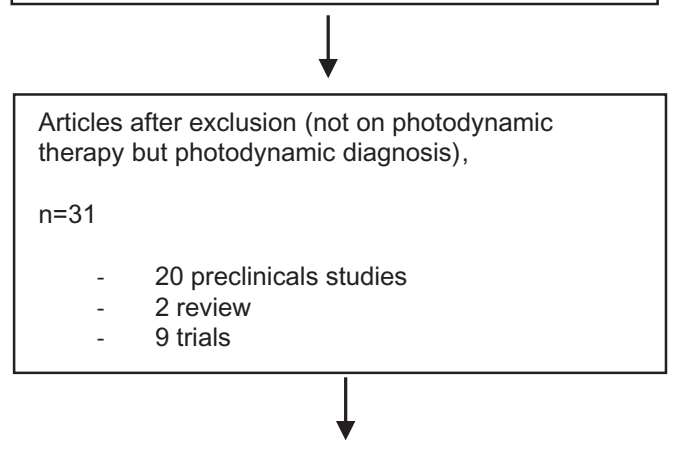

Full texts articles, $n=27$ articles included in this systematic review

19 preclinical studies

- 8 trials

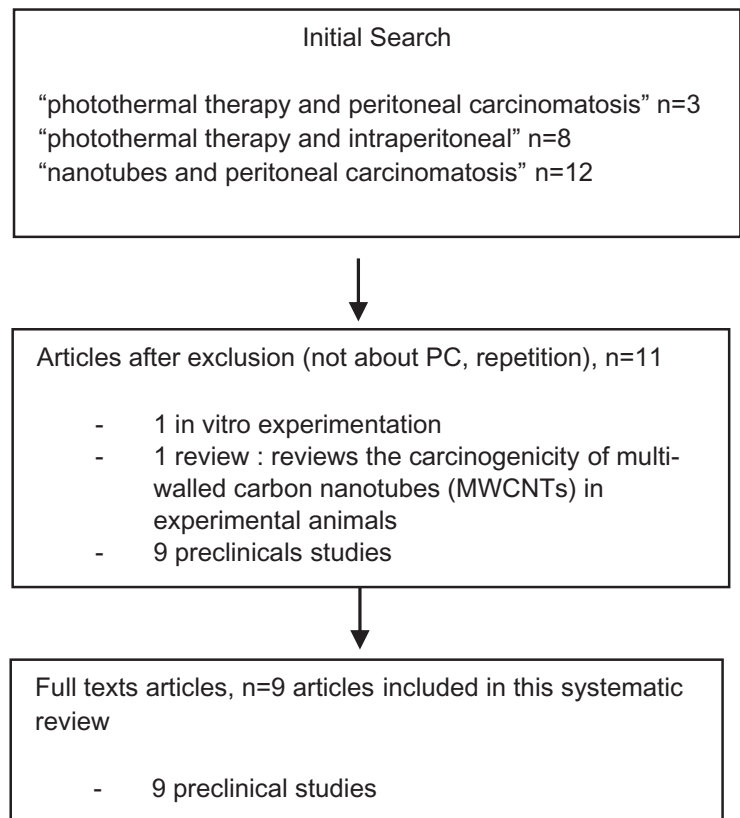

Figure 3: Flow chart.

\section{Photothermal therapy}

On PubMed, all studies proposed for "photothermal therapy and peritoneal carcinomatosis", "photothermal therapy and intraperitoneal", or "nanotubes and peritoneal carcinomatosis" were analyzed. Titles and abstracts were first evaluated to exclude articles not about PC. Eleven articles were first included. After exclusion of in vitro experimentation and review, to analyze only preclinical studies and trials, we really included nine articles.

\section{Results}

\section{Photodynamic therapy}

\section{Preclinical studies (Table 1)}

We included 27 articles in this review with 19 pre-clinicals studies. PM origins varied: 9 ovarian, 4 colonic, 2 gastric, 1 sarcomatosis, 1 pancreatic carcinomatosis, and 2 without carcinomatosis (Table 1). Results are presented in Table 1. We divided these articles by the PS used and the type of study: phase 1 corresponding in pharmacokinetics and toxicity study, phase II corresponding in efficacity and safety study, and phase III in survival study. Three generations of PS are described. The first generation consisted only in Photofrin ${ }^{\circ}$, hematoporphyrin derivative. Second and third generation PS were designed to improve tumor uptake, specificity of action and to reduce general toxicity. Before 1995, Photofrin ${ }^{\circ}$ was the only PS used. PDT for treatment of ovarian carcinomatosis with Photofrin $^{\circ}$ was first described in a mouse model in 1985 by Tochner [17]. He demonstrated the effectiveness of PDT with Photofrin ${ }^{\circ}$ with a high cure rate of $85 \%$, a decrease in abdominal size (26 of 29 had a marked reduction in abdominal girth) and an impact on the survival (6 of 15 of twice-treated group were alive at 90 days and considered cured). This author validated the tolerance of this treatment in a phase I preclinical study [32]: dogs received Photofrin ${ }^{\circ}$ both intravenously and intraperitoneally before IP light treatment. All dogs tolerated the treatment without significant morbidity. Perry [33] validated the tolerance and the tumor PS concentration in an other phase I study in 1991. The route of sensitizer administration (intravenous versus IP) did not significantly affect tumor sensitizer levels, toxicity, or mortality, with a maximal tolerated light dose at $1.04 \mathrm{~J} / \mathrm{cm}^{2}$. Griffin [34] validated in an other phase I the tolerance of this treatment.

With the arrival of second generation of PS, especially Foscan $^{\circ}$ (meta(tetrahydroxyphenyl)chlorin $=$ mTHPC) and hexaminolevulinate (HAL), other authors interested in the effective of PDT for PM. Morlet [35], first, evaluated PDT with MTHPC in this indication. He demonstrated that tumor-selectivity decreased with time and concluded that 


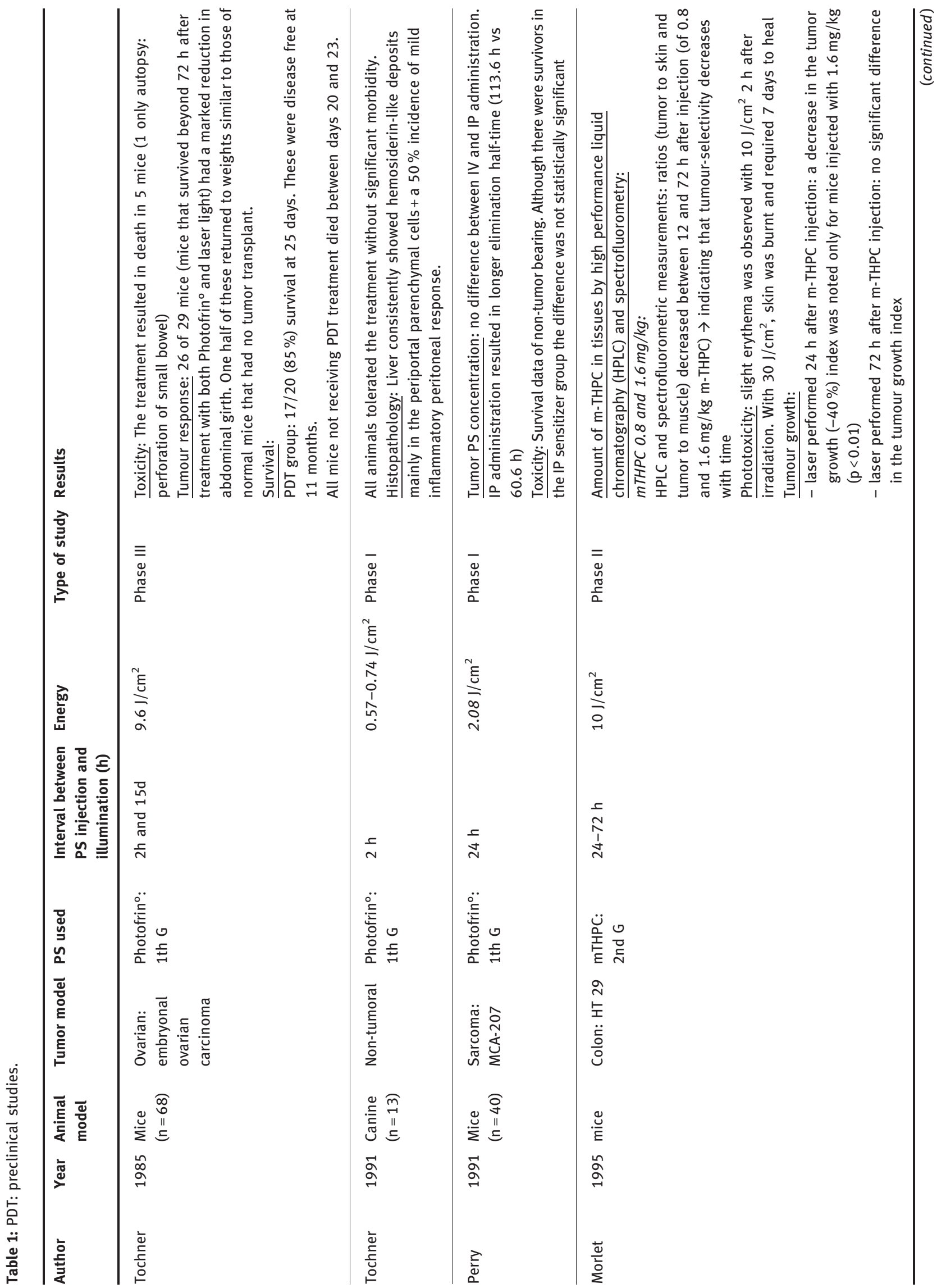




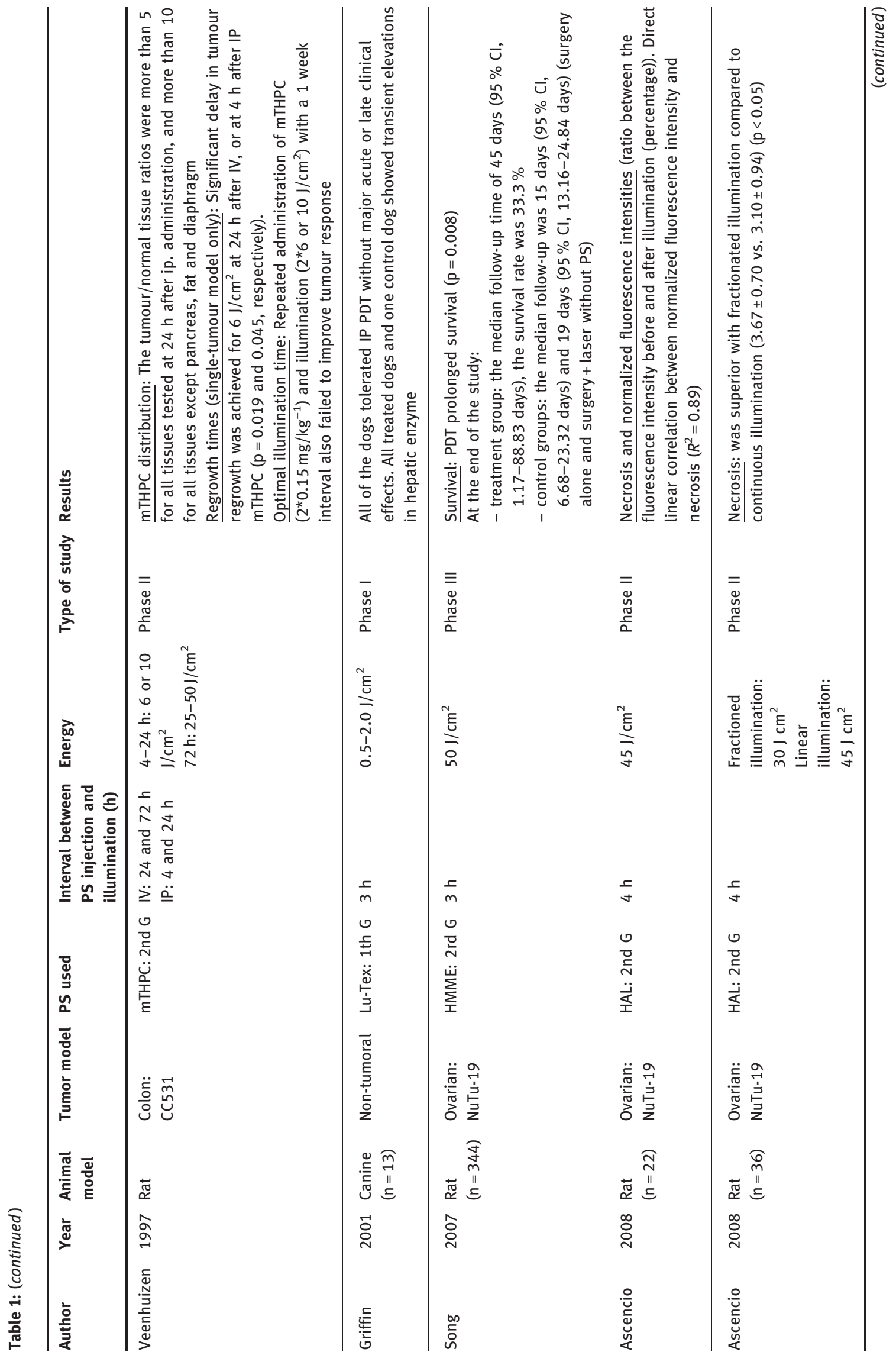




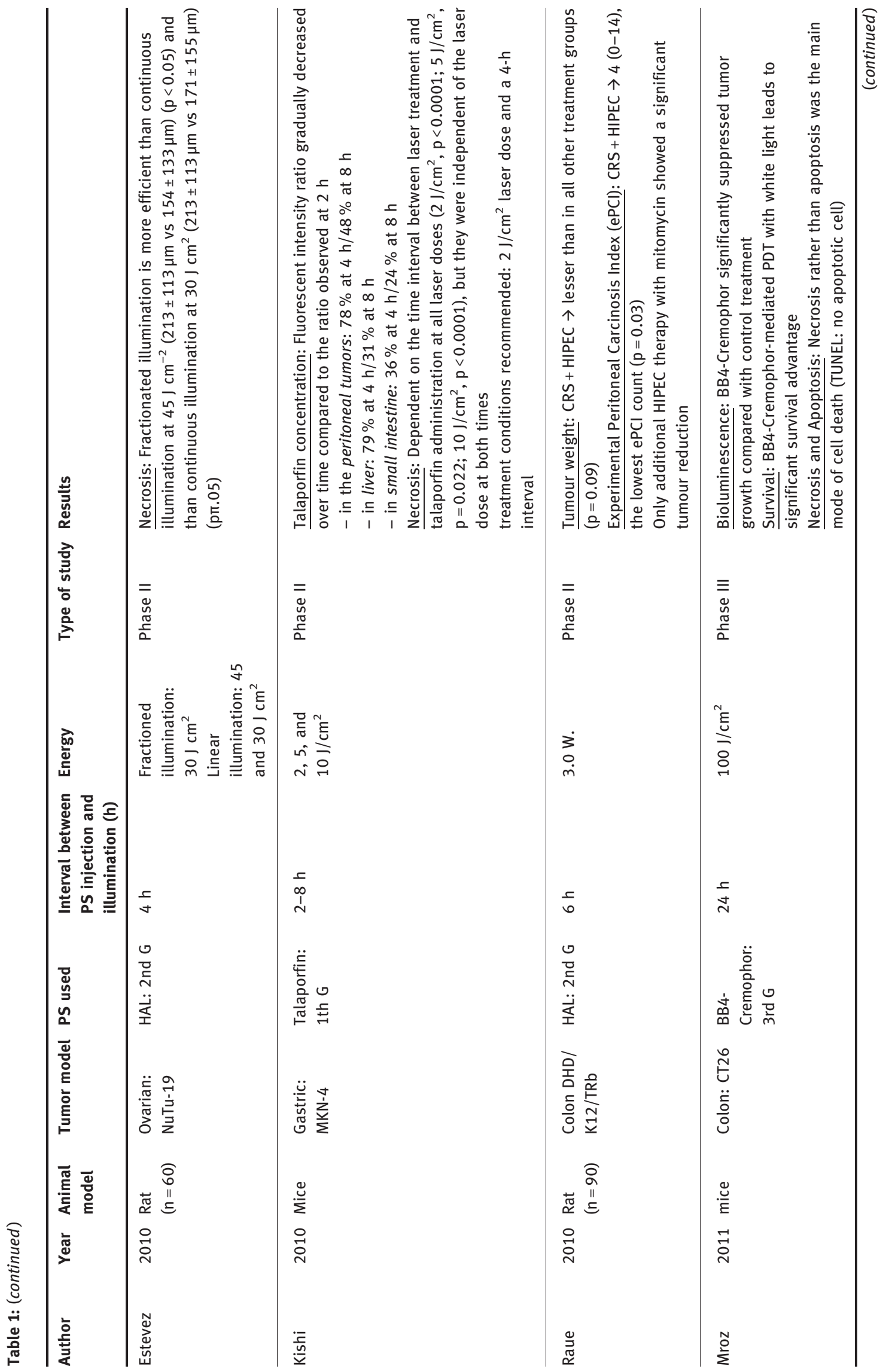




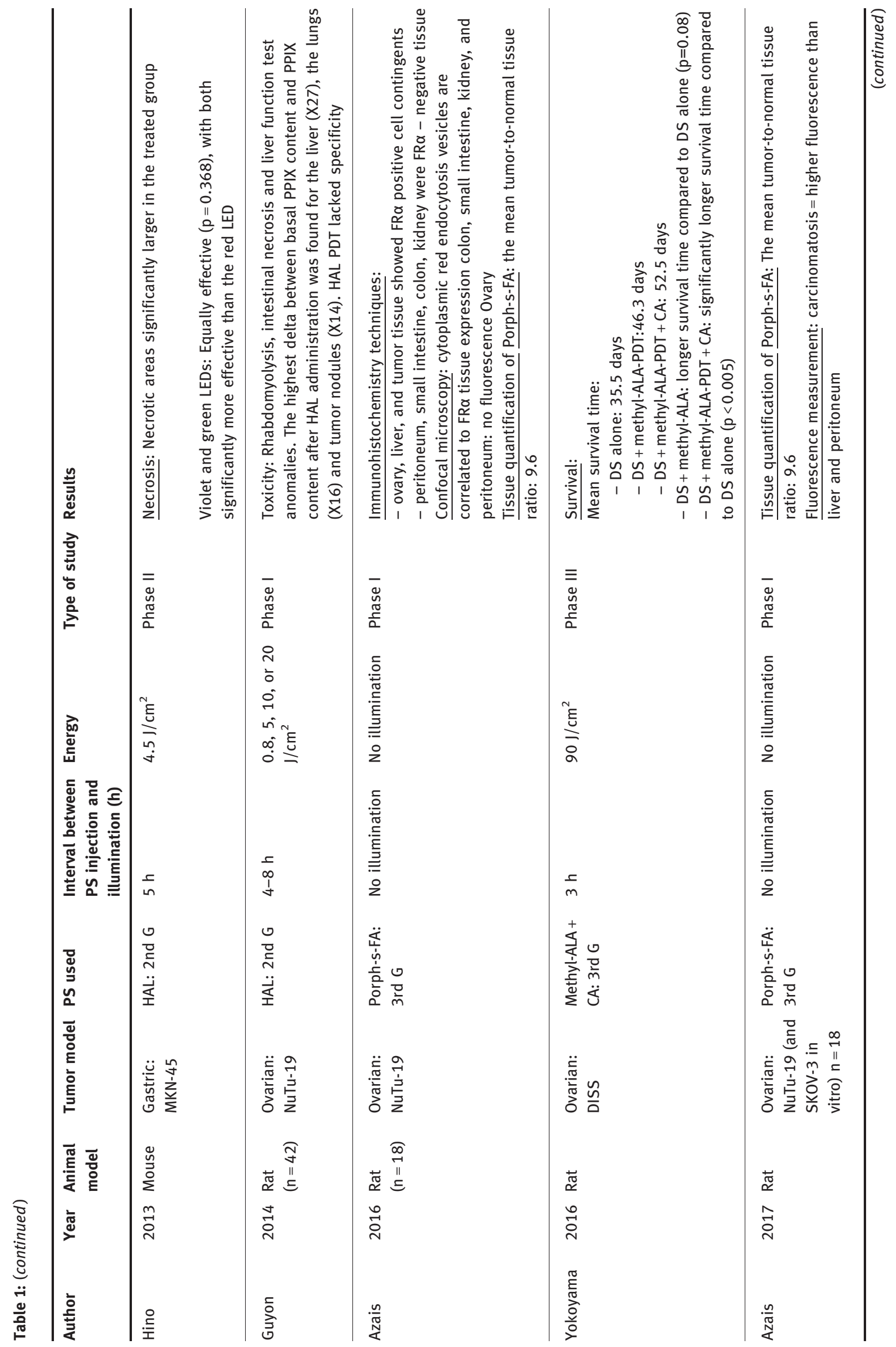


DE GRUYTER

Pinto and Pocard: Nano, phototherapy in CRC peritoneal metastasis $\longrightarrow \mathbf{9}$

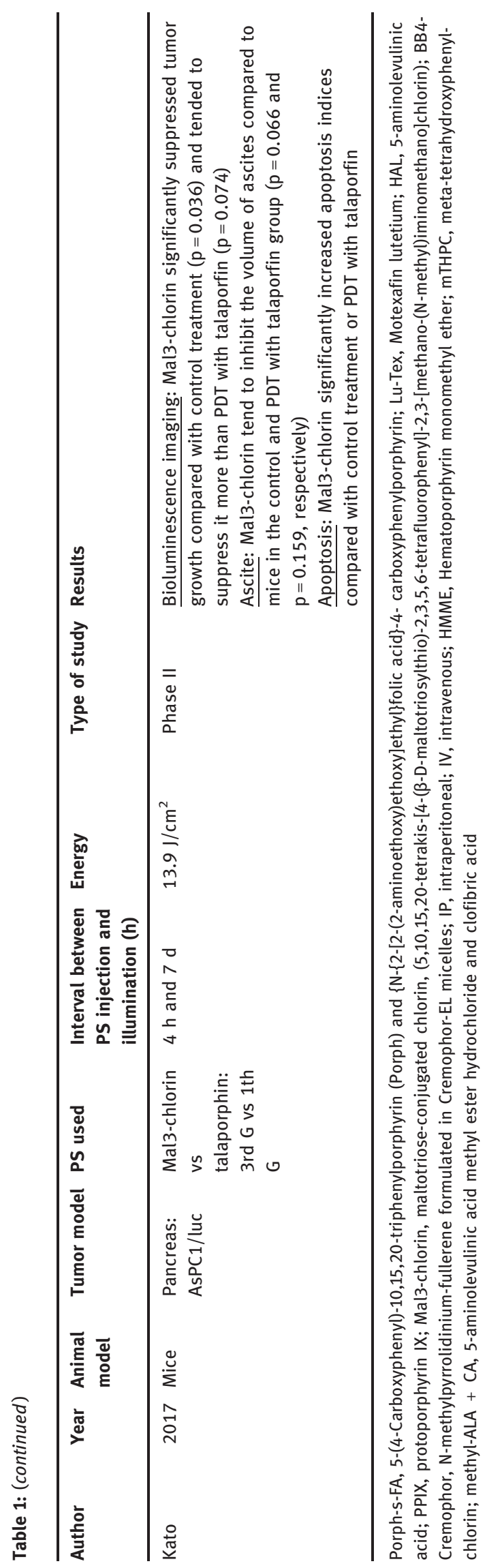


PDT results were better $24 \mathrm{~h}$ after drug administration than at $72 \mathrm{~h}$ (tumor growth decrease, $-40 \%$, with $1.6 \mathrm{mg} / \mathrm{kg}$ mTHPC injected $24 \mathrm{~h}$ before irradiation). Veenhuizen [36] showed that IP injection of PS permitted a better tumor biodistribution than IV injection. An uptake of up to $40 \%$ of the MTHPC injected dose was found per gram tumor at $4 \mathrm{~h}$ after an IP injection, and this resulted in very high (>14) concentration ratios of tumor to normal tissues. Low uptake was found after the IV injection route $(1 \%$ of the injected dose per gram tumor) with lower tumor/normal tissue ratios $(<8)$. The impact of the type of illumination was evaluated by Ascensio [37] and Estevez [38]. Ascensio [37] compared illumination after PS intraperitoneally injection in rats with ovarian PM, and concluded to the superiority of fractioned illumination compared to continuous illumination (necrosis value: $3.7+-0.7$ vs $3.1+-0.9$, $\mathrm{p}<0.05)$. He showed the direct linear correlation between necrosis and normalized fluorescence too [38]. Estevez [39] validated these results with a more important tumoral necrosis with fractioned illumination vs continuous illumination (at $45 \mathrm{~J} / \mathrm{cm}^{2}: 213 \pm 113 \mu \mathrm{m}$ vs $154 \pm 133 \mu \mathrm{m}, \mathrm{p}<0.05$, and at $\mathrm{J} / \mathrm{cm}^{2}$ : $213 \pm 113 \mu \mathrm{m}$ vs $\left.171 \pm 155 \mu \mathrm{m}, \mathrm{p}<0.05\right)$. Ascencio showed Song [40], combining CRS with PDT, was the first to demonstrate in a phase III study, a survival improvement (CRS + PDT 45 days versus 15 days with CRS alone, $\mathrm{p}<0.01$ ) with a 2nd generation of PS. Raue [41] compared in a phase II study, the association of CRS with PDT (PS: 2nd) vs HIPEC (mitomycin). Only additional HIPEC therapy with mitomycin showed a significant tumor reduction (tumor weight and Experimental Peritoneal Carcinosis Index). The real limit of the PDT with 2nd negation of PS was the toxicity. It was particularly induced by the lack of specificity of PS for tumor tissue. Mroz [42] reported death in all mice illuminated with red light. Guyon [43] shown that PDT with HAL induced rhabdomyolysis, intestinal necrosis and liver function test anomalies, leading to death in 2 out of 34 rats.

To solve this problem, the ultimate generation of PS was developed, consisting in targeted PS [44-46].

Azaiis [44, 45] conjugated PS with folate: folate receptor appeared like a promising target for epithelial ovarian cancer targeted therapy. He demonstrated in a phase I the good intra tumor biodistribution of this new PS (mean tumor-to-normal tissue ratio: 9.6).

Yokoyama [46] demonstrated, in the only phase III study with a new generation of PS (the methyl-ALA PDT + CA), a survival improvement. Adjunction of clofibric acid (a peroxisome proliferator-activated receptor $\alpha$ ligand) in CP from ovarian cancer permitted to improve rats survival compared to other treated rats, mainly CRS alone (mean survival time: 52.5 days vs 35.5 days).

\section{Clinical trials (Table 2)}

Height trials were published on the PM treatment by PDT: 3 phase I and 5 phase II. PC origin was different in each trial: PC from ovarian cancer, digestive origin, primary peritoneal carcinoma, sarcoma. The majority of these trials (7/8) evaluated Photofrin ${ }^{\circ}$ mediated IP PDT.

\section{- Phase I:}

Sindelar [47] demonstrated successfully delivered to all peritoneal surfaces in all 23 patients in whom debulking was technically possible. Major complications of the procedure (CRS + PDT) included intestinal fistulas (2/23), postoperative hemorrhage $(1 / 23)$, necrotizing pancreatitis $(1 / 23)$, and ureteral leakage (1/23). We noted that $6 / 23$ patients remained free of evidence of recurrent disease for up to 18 months after IP PDT.

Delanay [48] demonstrated the feasibility of delivering PDT to the peritoneal cavity at the time of laparotomy after debulking surgery in patients with disseminated IP tumors. Of the 54 patients in the study population, 39 underwent successful debulking and intraoperative PDT using Photofrin ${ }^{\circledR}$. He described the maximum tolerated dose of PDT given $48 \mathrm{~h}$ after intravenous administration of Photofrin ${ }^{\circledR}(2.5 \mathrm{mg} / \mathrm{kg}), 3.75 \mathrm{~J} / \mathrm{cm}^{2}$ of green light with boosts of green light $\left(5.0-7.5 \mathrm{~J} / \mathrm{cm}^{2}\right)$ or red light $\left(10-15 \mathrm{~J} / \mathrm{cm}^{2}\right)$. There were no operative or postoperative deaths in this series. Major morbidity was seen in 9/39 (23\%) of patients undergoing surgery and PDT $(n=3$ bowel perforations, $\mathrm{n}=2$ prolonged intubation, and $\mathrm{n}=1$ gastric perforation, colo cutaneous fistula, postoperative hemorrage, pancreatitis, and ureteral injury). There were an increased number of postoperative pleural effusions in patients undergoing PDT, compared to those just being explored (CRS/PDT-: 3/15 (20\%) vs CRS + PDT: 23/39 (59\%), $\mathrm{p}=0.01)$. Thirty-one patients $(80 \%)$ had no evidence of disease recurrence at 2-3 months follow-up. The median survival of patients who received PDT was 30 months.

Wierrani [49], investigated PDT with mTHPC (the only clinical trial with a 2nd generation of PS) in eight patients with recurrent gynecological cancer that metastased to the peritoneum. One patient died 2 days postoperatively secondary to heart failure. This treatment appeared like tolerable with limited side effects

- Phase II:

All phase II trials evaluated toxicity and effectiveness of IP PDT in PC. Patients received Photofrin $2.5 \mathrm{mg} / \mathrm{kg}$ i.v. $48 \mathrm{~h}$ before debulking surgery (CRS). The most important adverse effect described in each trial was the capillary leak syndrome. It is characterized by a body weight gain 


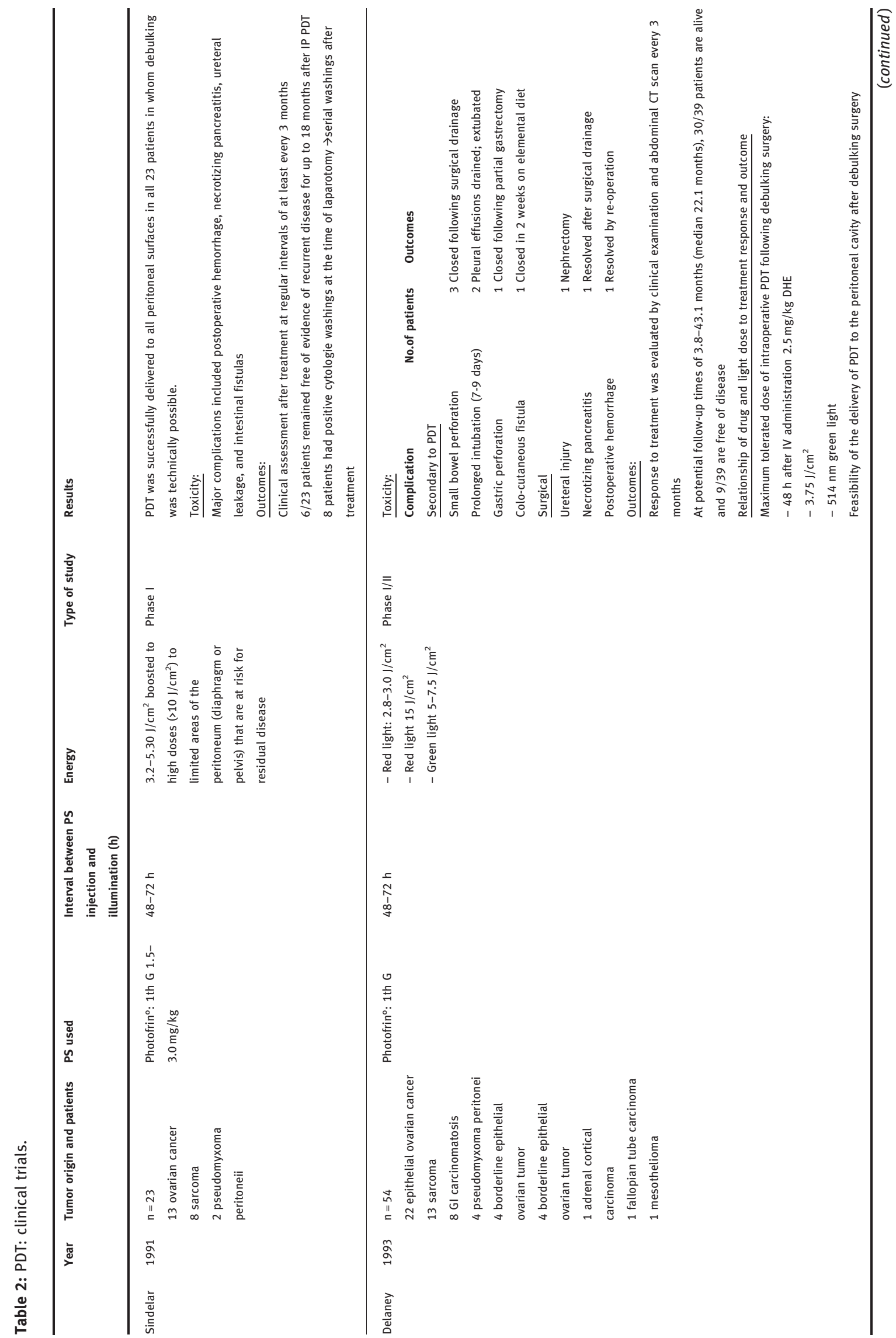




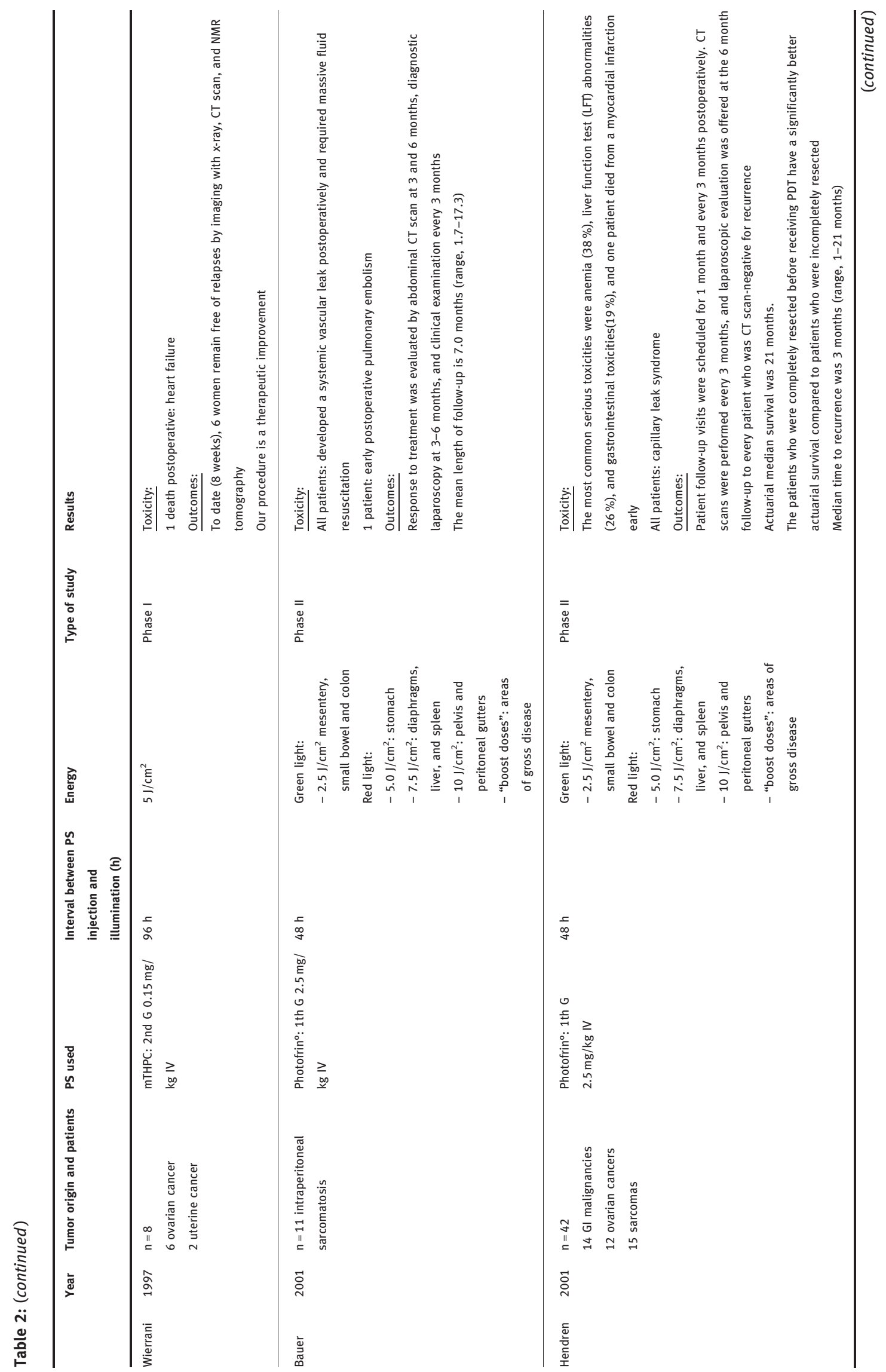




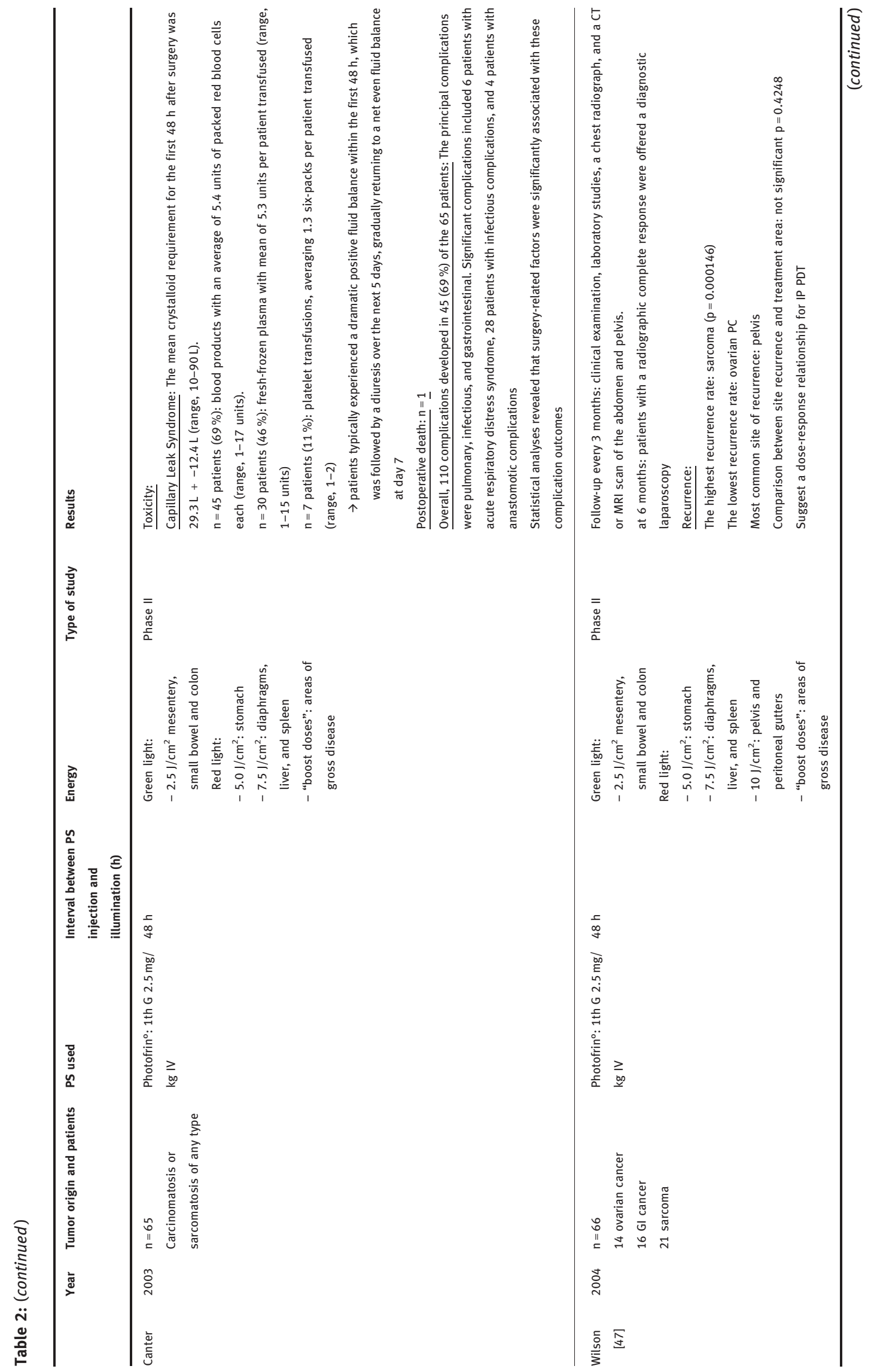




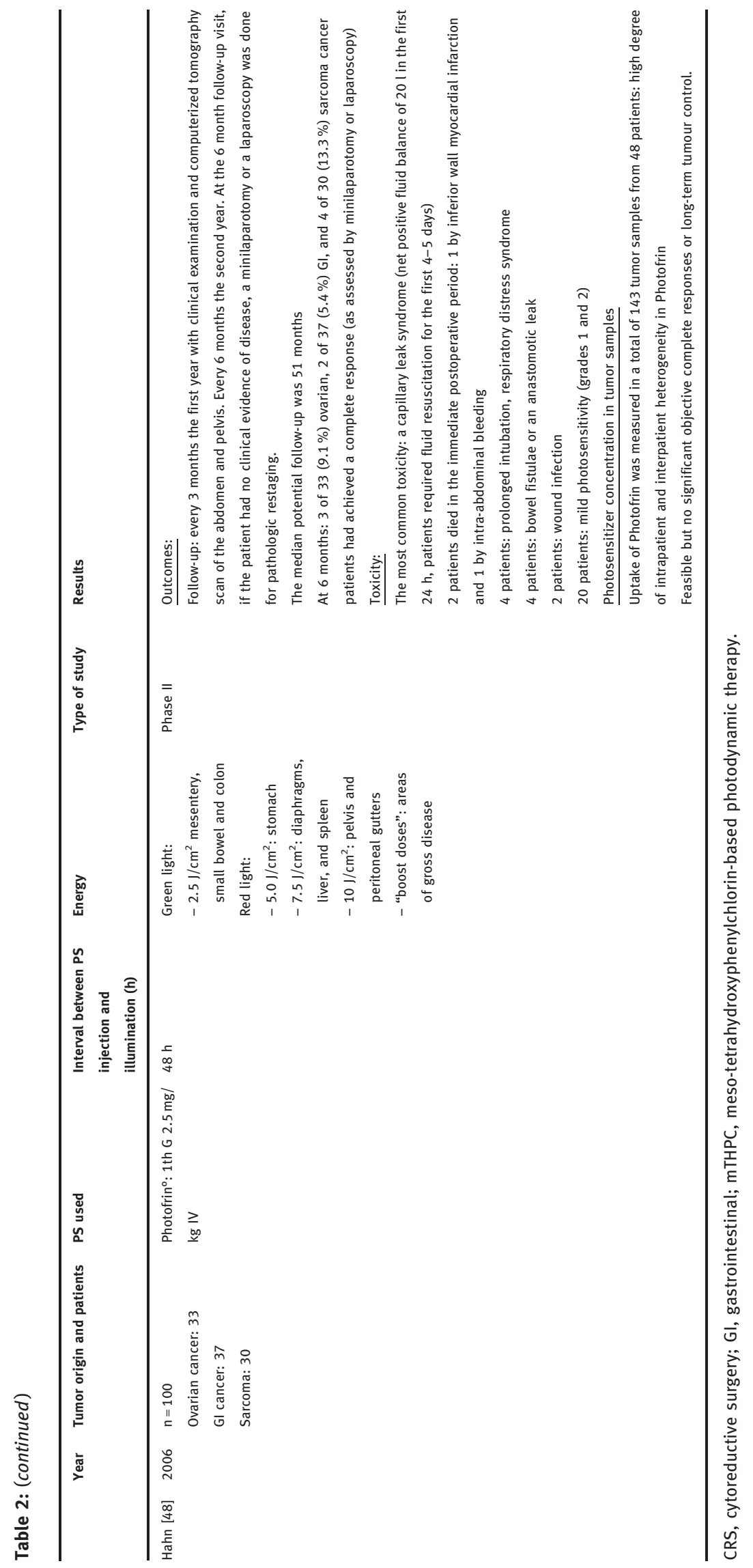


of $15-20 \%$ and requiring intensive care management and volume resuscitation.

Bauer [50] demonstrated that all patients $(n=11)$ developed a systemic vascular leak postoperatively. This toxicity appeared to be worse in patients who required the most extensive debulking. One patient suffered an early postoperative pulmonary embolism. Five patients ( $45 \%$ ) have no evidence of disease at follow-up (range, 1.7-17.3 months), four patients (36\%) are alive with disease progression and two patients $(18 \%)$ died from disease progression.

Canter [51] included 65 patients. Significant complications included 6 patients with acute respiratory distress syndrome, 28 patients with infectious complications, and 4 patients with anastomotic complications. Fluid requirement for the patients during the first $48 \mathrm{~h}$ was important: the mean crystalloid requirement was $29.3 \mathrm{~L}, 49$ patients required blood products, 30 patients required fresh-frozen plasma, and 7 patients received platelet transfusions. Other complications developed in $45(69 \%)$ of the 65 patients: the principal complications were pulmonary, infectious, and gastrointestinal (pancreatitis/pancreatic leak in three patients, two whom underwent distal pancreatectomy, enterocutaneous fistulae in two patients, and peritoneovaginal fistula in one patient). Statistical analyses revealed that surgery-related factors were significantly associated with these complication outcomes (a greater number of nodules removed and larger body mass index, defined as continuous factors, were both significantly associated with a greater risk of pulmonary complications).

Hendren [52] included 42 patients and described common serious toxicities: anemia (38\% of patients), transient LFT abnormalities (26\%), and bowel obstruction or other GI abnormalities (19\%). All patients developed the capillary leak syndrome perioperatively. One patient had a serious pulmonary embolism, three patients developed intra-abdominal abscesses, and two patients developed fistulae. One patient died from a myocardial infarction early. The median follow-up was 21 months with a better survival for patients receiving completely cytoreductive surgery before PDT $(\mathrm{p}=0.015)$.

Wilson [53] enrolled 66 patients. Forty-five, and 49 patients were evaluable for response rates, and patterns of recurrence, respectively. Eleven of 45 patients showed no evidence of recurrence 3 months after treatment. The pelvis was the site with the highest rate of recurrence after IP PDT, 19 of 49 (39\%) patients. The highest recurrence was seen in sarcoma patients (19 of 82 sites) and the lowest was seen in ovarian cancer patients (8 of 47 sites).

Hahn [54] described the most important phase II trial with 100 patients. Two patients died in the immediate postoperative period from bleeding, sepsis, adult respiratory distress syndrome, and cardiac ischemia. The most common adverse effect related was capillary leak syndrome. Twenty patients developed skin photosensitisation. The median follow-up was 51 months. All 100 patients had progressed by the time of statistical analysis. The median failure-free survival and overall survival by strata were ovarian, 2.1 and 20.1 months; gastrointestinal cancers, 1.8 and 11.1 months; sarcoma, 3.7 and 21.9 months. No significant objective complete responses or long-term tumor control was found. Heterogeneity in PS uptake and tumor oxygenation, lack of tumor specificity for PS uptake, and the heterogeneity in tissue optical properties may account for the lack of efficacy observed.

Since 2006, no more trial evaluating PDT for PM treatment was published.

On Clinical trials, when we searched "photodynamic therapy and peritoneal carcinomatosis", 2 studies were proposed. The first was about photodynamic diagnosis and not therapy. The second consisted in a prospective follow-up of outcomes in patients receiving PDT for neoplastic diseases (head and neck cancer, pleural malignancies, PM or sarcomatosis, and prostate cancer). They would like to retrospectively review treatment parameters of all patients who undergo/underwent PDT. Recruiting started in 2011, until 2021. Survival and disease free (10 years) were two objectives.

\section{Photothermal therapy}

PTT for the treatment of peritoneal dissemination of colorectal cancer was first proposed by Levi-Polyachenko [55] in 2009 using localized carbon nanotubes stimulated with infrared light. Carbon nanotubes have special electrical, optical, and thermal characteristics due to the arrangement of the carbon atoms confined in nanometer sized volumes. They can influence the electric field in their localized area, which enhances absorption of electromagnetic energy and generates rapid heating of the tube.

Nine preclinical studies were published on IP PTT: 4 phase I, 3 phase II and 2 phase III (Table 3).

\section{- Phase I:}

Three authors [56-58] evaluated multi-wall carbon nanotubes (MWCNT) and one gold NPs toxicities. The incidence of peritoneal mesothelioma was a controversial analysis after MWCNT administration. Whereas Takagi [56] and Rittinghausen [57] described an important mortality after MWCNT with an important incidence of mesothelioma at necropsy (until $98 \%$ mice treated with 
Table 3: Photothermal therapy (PTT): preclinical studies.

\begin{tabular}{|c|c|c|c|c|c|}
\hline Author & Year & $\begin{array}{l}\text { Animal } \\
\text { model }\end{array}$ & Nanoparticles & $\begin{array}{l}\text { Type of } \\
\text { study }\end{array}$ & Results \\
\hline Takagi & 2008 & $\begin{array}{l}\text { Mice } \\
(n=76)\end{array}$ & MWCNT & Phase I & $\begin{array}{l}\text { The highest mortality, MWCNT group followed by the Crocidolite group } \rightarrow \\
\text { study was terminated at week } 25 \text { ( } 180 \text { days) } \\
\text { MWCNT induced mesothelioma along with Crocidolite (positive control) }\end{array}$ \\
\hline Muller & 2009 & Rat & MWCNT & Phase I & $\begin{array}{l}\text { After } 24 \text { months, MWCNT with or without structural defects did not induce } \\
\text { mesothelioma ( } 4 \text { or } 6 \% \text {, respectively). while Crocidolite induced a clear } \\
\text { carcinogenic response ( } 34.6 \% \text { animals with mesothelioma vs } 3.8 \% \text { in vehicle } \\
\text { controls). } \\
\text { The incidence of tumors other than mesothelioma was not significantly } \\
\text { increased across the groups }\end{array}$ \\
\hline Zhang & 2010 & Mice & $\begin{array}{l}\text { Gold } \\
\text { nanoparticles }\end{array}$ & Phase I & $\begin{array}{l}\text { Gold nanoparticles at low concentrations do not cause appreciable toxicity } \\
\text { Obvious effects on organ index have been observed at high concentration. } \\
\text { Toxicity: More important for orally administration (significant decreases in } \\
\text { body weight, spleen index, and red blood cells) and intraperitoneal routes } \\
\text { than IV injection }\end{array}$ \\
\hline Bagley & 2013 & Mice & PEG-NRs & Phase II & $\begin{array}{l}\text { Toxicity and effectiveness of implanted NIR illumination source: } \\
\text { - Initial temperature change after } 50 \mathrm{~s} \text { of direct implanted NIR illumination in } \\
\text { (e) tumors, (f) intestine, and (g) liver } \rightarrow \text { More important in PEG-NR treated } \\
\text { animals versus controls } \\
- \text { Maximal temperature change for tumor, liver, and intestine of PEG-NR } \\
\text { treated animals ( } \mathrm{n}=5 \text { per tissue) } \rightarrow \text { significant accumulation of PEG-NRs in } \\
\text { the liver } \\
\text { - Histology and Ki- } 67 \text { immunohistochemical staining of tissues following } \\
\text { PEG-NR therapy with implanted NIR device. } \\
\text { No tissue damage or proliferative defects in intestine/Thermal effects were } \\
\text { more modest than in ovarian tumors or the liver } \\
\text { - Quantification of doxorubicin-loaded liposomes and AngioSPARK750 in } \\
\text { tumor } 3 \mathrm{~h} \text { after injection and PEG-NR/Implant NIR therapy or injection only } \\
\rightarrow \text { concentration was superior for PEG-NRs + implant NIR }\end{array}$ \\
\hline
\end{tabular}

Rittinghausen 2014 Rats MWCNT Phase I Mortality: At the end of the experimental time after 24 months mortality was:
$(\mathrm{n}=500)$

$80 \%$ in the MWCNT A and B low- and high-dose groups and in the MWCNT C high-dose group $56 \%$ in the MWCNT D low-dose group $76 \%$ in the amosite asbestos group (positive control) and $34 \%$ in the negative control group Histopathological findings:

$\rightarrow$ Malignant mesotheliomas of the peritoneum MWCNT A groups: $98 \%$ (high-dose) and $90 \%$ (low-dose) MWCNT B groups: $90 \%$ (high dose) and $92 \%$ (low dose) MWCNT C groups: $94 \%$ (high dose) and $84 \%$ (low dose) MWCNT D groups: $70 \%$ (high dose) and $40 \%$ (low dose) Amosite asbestos group: $66 \%$ Medium control group: 1 mesothelioma (2\%) $\rightarrow$ granulomas on the peritoneal surface: most of the MWCNT-treated rats

\begin{tabular}{|c|c|c|c|c|c|}
\hline $\begin{array}{l}\text { Diddens- } \\
\text { Tschoeke }\end{array}$ & 2015 & $\begin{array}{l}\text { Mice } \\
(\mathrm{n}=34)\end{array}$ & $\mathrm{PdNc}(\mathrm{OBu}) 8$ & Phase II & $\begin{array}{l}\text { Histology/Necrosis: In contrast to the control groups, the central area of the } \\
\text { tumor tissue treated during } 15 \text { and } 20 \mathrm{~s} \text { was completely necrotic. Adjacent } \\
\text { peripheral normal tissue including skin and muscle remained completely } \\
\text { unaffected. }\end{array}$ \\
\hline
\end{tabular}


Table 3: (continued)

\begin{tabular}{|c|c|c|c|c|c|}
\hline Author & Year & $\begin{array}{l}\text { Animal } \\
\text { model }\end{array}$ & Nanoparticles & $\begin{array}{l}\text { Type of } \\
\text { study }\end{array}$ & Results \\
\hline Nowacki & 2015 & $\begin{array}{l}\text { Mice } \\
(n=60)\end{array}$ & $\begin{array}{l}\text { A0-o-CX-chem- } \\
\text { CD133 }\end{array}$ & $\begin{array}{l}\text { Phase } \\
\text { III }\end{array}$ & 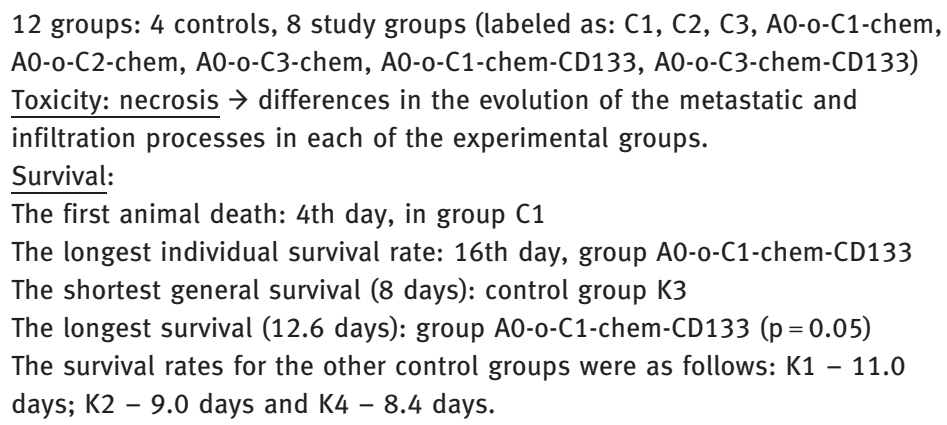 \\
\hline Wu & 2015 & Mice & pSGNs & Phase II & $\begin{array}{l}\text { Necrosis: Mice with ovarian PC, treated with pSGNs (OD } 800=1.5) \text { or } 10 \% \\
\text { trehalose and irradiated with an } 808-n m \text { NIR laser } \rightarrow \text { IP lavage } \rightarrow \text { annexin V } \\
\text { and propidium iodide } \\
\text { The percentage of necrosis in cancer cells was significantly increased in the } \\
\text { groups that received IP PTT mediated by pSGNs } \\
\text { Toxicity: damage of normal tissues in the intraperitoneal cavity } \rightarrow \text { TUNEL assay } \\
\text { No noticeable damage in normal tissues (liver, kidney, spleen, intestinal } \\
\text { epithelium) } \\
\text { Chemoluminescent intensity: The NIR laser irradiation was repeated every } \\
\text { 3-4 days. IP administered pSGNs combined with NIR laser irradiation } \\
\text { significantly inhibited tumor growth compared with the control, NIR-only, and } \\
\text { pSGNs-only groups in both tumor cell } \\
\text { models. Repeated PTT can inhibit IP tumor growth in vivo. } \\
\text { Conjugating pSGNs with anti-human CD47 monoclonal antibody: } \\
\text { The group treated with anti-human CD47 conjugated pSGNs and NIR laser } \\
\text { irradiation had the strongest therapeutic effect on the human ovarian cancer } \\
\text { cell xenograft model. }\end{array}$ \\
\hline Zhang & 2018 & Mice & C-GERTs & $\begin{array}{l}\text { Phase } \\
\text { III }\end{array}$ & $\begin{array}{l}\text { Toxicity: Histological analysis of major organs (liver, lung, kidney, heart, and } \\
\text { spleen) } \rightarrow \text { no obvious signs of toxicity are found in the harvested organs } \\
\text { Bioluminescence: The C-GERTs + laser group shows the best therapeutic } \\
\text { effect, with near complete elimination of tumors and suppression of regrowth } \\
\text { Total flux (TF) value } 20 \text { th days: } \\
\text { - saline and cisplatin: increased to more than } 600 \% \text { of the initial value } \\
\text { - C-GERTs + laser group: near complete elimination of tumors and suppression of } \\
\text { regrowth; average TF value decreased to about } 37 \% 20 \text { days after treatment. } \\
\text { The extent of tumor dissemination in the abdominal cavities: significant } \\
\text { reduction in tumor number, size, and weight in the GERTs + laser group } \\
\text { GERTs + laser group: few small intra-abdominal tumors ( } 5 \text { per mouse). } \\
\text { C-GERTs + laser group: } 80 \% \text { of mice were completely cured, with just } 2 \text { mice } \\
\text { found to have } 1 \text { small tumor remaining each. } \\
\text { The average tumor weight in the C-GERTs + laser group was significantly } \\
\text { reduced to } 0.03 \pm 0.05 \text { g per mouse } \rightarrow \text { tumor weights in the saline }+ \text { laser, } \\
\text { cisplatin, C-GERTs, and GERTs + laser groups ( } \approx 0.80 \pm 0.14,0.55 \pm 0.08 \text {, } \\
0.41 \pm 0.06 \text {, and } 0.18 \pm 0.15 \text { g per mouse, respectively) } \\
\text { Survival: The C-GERTs + laser group achieves a survival rate of } 100 \% \text { during } \\
\text { the observation period ( } 35 \text { days). All mice in the other four groups eventually } \\
\text { succumbed to their tumors, with survival times of } 26.33 \pm 2.05,24 \pm 1.63 \text {, } \\
25.33 \pm 2.05 \text {, and } 31.67 \pm 1.25 \text { days for saline + laser, cisplatin, C-GERTs, and } \\
\text { GERTs + laser groups, respectively }\end{array}$ \\
\hline
\end{tabular}

PdNc(OBu)8, Palladium 5,9,14,18,23,27,32,36-octabutoxynaphthalocyanine; MWCNT, multi-wall carbon nanotubes; A0-o-CX-chem-CD133, nanovehicles based on anti-CD133 antibodies bioconiugated to carbon nanotubes loaded with platinum (Pt) -prodrugs; PEG-NRs, polyethylene glycolcoated gold nanorods; pSGNs, pegylated silica-core gold nanoshells; C-GERTs, cisplatin-loaded gap-enhanced Raman tags; IV, intravenous; IP, intra peritoneal 
high dose); Muller [58] did not note this incidence. In a rat experimentation, after 24 months follow-up, MWCNT with or without structural defects did not induce mesothelioma ( 4 or $6 \%$, respectively), while Crocidolite induced a clear carcinogenic response (34.6\% animals with mesothelioma vs $3.8 \%$ in vehicle controls). Gold NPs didn't induce mesothelioma but obvious effects on organ index had been observed at high concentration [59]. Toxicity was more important for orally administration (significant decreases in body weight, spleen index, and red blood cells) and IP routes than IV injection.

\section{- Phase II:}

Bagley [60] described a strategy combining systemically delivered plasmonic nanomaterials with intraperitoneally implanted NIR illumination sources. In mouse models of orthotopic ovarian cancer pretreated with PEG-NRs (polyethylene glycolcoated gold nanorods), delivery of NIR light via the implanted device selectively elevated the temperature of ovarian tumors. Data illustrated that synergies between plasmonic nanomaterials and novel NIR illumination methods could achieve selective and tolerable photothermal effects in complex anatomical environments. He demonstrated that localized plasmonic heating of ovarian tumors can enhance accumulation of therapeutic agents including doxorubicin liposomes in this orthotopic tumor model.

Diddens-Tschoeke [61] showed PTT effectiveness in subcutaneous tumoral model after IP injection of NPs. In contrast to the control groups, the central area of the tumor tissue treated during 15 and 20 s was completely necrotic, without necrosis on adjacent organs.

$\mathrm{Wu}$ [62] repeatedly performed noninvasive PTT mediated by pegylated silica-core gold nanoshells (pSGNs) in vivo with external NIR laser irradiation. Mice were treated with $808 \mathrm{~nm}$ of NIR laser irradiation in five areas on the abdomen. The number of annexin V/PI double-positive cancer cells in the group that received PTT was twice as high as that of the other groups $(p=0.0024$, $\mathrm{NIR}+$ pSGNs vs control; $\mathrm{p}=0.007, \mathrm{NOR}+\mathrm{pSGNs}$ vs NIR only; $\mathrm{p}=0.0034$, NIR + pSGNs vs pSGNs only). In addition, no cell damage in IP vital organs was observed on the basis of a TUNEL assay and Ki-67. Chemoluminescence analysis showed that pSGNs IP administered combined with NIR laser irradiation significantly inhibited tumor growth compared with the control, NIR-only, and pSGNsonly groups in both tumor cell models. Repeated PTT inhibited IP tumor growth in vivo. The group treated with anti-human CD47 conjugated pSGNs and NIR laser irradiation had the strongest therapeutic effect on the human ovarian cancer cell xenograft model.
- Phase III

Nowacki [63] compared mice survival with PC, treated by 12 different possibilities: 4 controls, 8 study groups (labeled as: C1, C2, C3, A0-o-C1-chem, A0-o-C2-chem, A0o-C3-chem, A0-o-C1-chem-CD133, A0-o-C3-chem-CD133). A0-o-C1-chem consisted in nanovehicles based on antiCD133 antibodies bioconiugated to carbon nanotubes loaded with platinum (Pt) -prodrugs. The longest survival (12.6 days) was obtained by A0-o-C1-chem-CD133 group $(p=0.05)$, whereas the survival rates for the other control groups were as follows: K1 - 11.0 days; K2 - 9.0 days and K4 - 8.4 days.

Zhang [64] in a recent phase III study, evaluated C-GERTs-based chemo-photothermal synergistic therapy for treatment of advanced ovarian cancers. He didn't found obvious signs of toxicity in the harvested organs, but a best therapeutic effect, with near complete elimination of tumors and suppression of regrowth for mice treated with C-GERTs + laser. C-GERTs consisted in cisplatinloaded gap-enhanced Raman tags. The C-GERTs + laser group achieves a survival rate of $100 \%$ during the observation period (35 days). All mice in the other four groups eventually succumbed to their tumors, with survival times of $26.33 \pm 2.05,24 \pm 1.63,25.33 \pm 2.05$, and $31.67 \pm 1.25$ days for saline + laser, cisplatin, C-GERTs, and GERTs + laser groups, respectively. These results demonstrated that CGERTs-based chemo-photothermal synergistic therapy can effectively control the spread of disseminated tumors in mice and has potential as a safe and powerful method for treatment of advanced ovarian cancers, to improve survival and life quality of patients.

\section{Discussion}

Residual microscopic metastases after cytoreductive surgery, remains a therapeutic challenge. HIPEC represents an efficient therapy but with an important morbidity. For many years others therapeutics were developed by the collaborations of physicists and surgeons. Technical innovations permit to treat tumor with more specificity to decrease morbidity. Peritoneal metastases present little penetration on the peritoneum, that represent an ideal indication for these news therapeutics which are PDT and PTT. The antitumoral target of these treatment is particularly explained by "the enhanced permeability and retention effect" (EPR effect). EPR effect is a concept by which molecules of certain sizes (typically liposomes, NPs, and macromolecular drugs) tend to accumulate in tumor tissue much more than they do in normal tissues [65]. The 
EPR effect is usually employed to describe NP and photosentizer delivery to cancer tissue [66]. PSs have an aromatic structure, which gives them a strong lipophilic character too. LDL has attracted attention as endogenous carrier of hydrophobic therapies (including certain antitumor). Indeed, the LDL-drug complexes are very effectively incorporated in the tumors, via receivers, which is an important factor of tumor selectivity. To improve this tumoral selectivity, antitumor vectors are coupled (new generation of PS).

PDT is older than PTT. Different PSs exist and have different indications. In France, Photofrin ${ }^{\circ}$ is indicated in the treatment of recurrence of non-small cells lung cancers or esophagus cancer having received prior regional treatment. In oncology, Foscan ${ }^{\circ}$ is indicated in palliative head and neck epithelial cancer, if others therapies aren't possible. The toxicity, especially cutaneous, have slowed the development of this therapy in others cancers. This review shows the safety, the effectiveness and specificity with better tumor-selectivity, shorter retention time, improvement of the therapeutic window and reduction of the associated phototoxicity, in preclinical studies. Only eight human clinical trials [47-54], mainly with first generation of PS (7/8), are published. The conclusion was that PDT after cytoreductive surgery is feasible without long-term tumor control and with a significant toxicity. The most frequent toxicity correspond in a capillary leak syndrome. It is characterized by a body weight gain of $15-20 \%$ and requiring intensive care management and volume resuscitation. But the majority of clinical trial (7/8) evaluated first generation of PS. We expect a decrease of toxicity and an improvement of efficacity with new generation of PS.

More recently PTT appeared as a new therapeutic in oncology. Plasmonic NPs are injected to induce a hyperthermia after laser illumination. In comparison with PDT, few articles analyze effectiveness of PTT in PC treatment. Only nine preclinical studies are published: 4 phase I [56-59], 3 phase II [60-62], and 2 phase III [63, 64]. MWCNT were first evaluate in phase I study. The correlation with peritoneal mesothelioma apparition and high mortality impacted the development of this therapy. Other NPs are used, like gold NPs or silica gold nanoshell. The association with another drug (chemotherapy: cisplatin or anti-CD133 antibodies) permitted to developed preclinical phase II studies with effective results in terms of tumoral necrosis or tumoral growth (bioluminescence). Two preclinical phase III validated the improvement of survival with PTT in comparison with chemotherapy, laser or control.

\section{Limitations}

This review is limited by the type of studies included: only preclinical and trials. We included a reasonable but limited number of articles. The number of phase III preclinical examination is limited ( $n=4$ for PDT and $n=2$ for PTT) and it is not possible to affirm the survival benefits of these treatment today. In addition, we know that animals models (mice mainly) do not always replicate the human results because of the biological differences.

For future trials, digestive toxicity with intestinal fistulas in the most important toxicity we fear with these news therapeutics. We know that PM are spread of mesentery and bowel, but it is important not to increase digestive perforation with vectorized treatment. It is the main limit we expect with these news targeted therapeutics. Others technical problems exist for clinical trial: does the treatment inject during hospitalization $48 \mathrm{~h}$ before surgery? Is the laser actually adapted for IP illumination? Is it easy to change the power during surgery (like in clinicals trials for PDT evaluation)? Is it necessary to adapt power of the laser function of digestive anastomosis during surgery? Or is it better to make illumination before anastomosis? Wavelength for PTT (in NIR light) need to have eyes protection. Is it possible to say that this therapy is safe for cargivers? What are the different risks of these therapies? These issues may complicate the development of these therapies in the clinic.

\section{Conclusions}

PDT and PTT are promising therapies to treat PM. PDT was evaluated since 1985 but the lack of specificity of PS limited the extension of this therapy. With the apparition of the new generation of PS, preclinical results showed a better tumoral biodistribution with an important tumor-tonormal tissue ratio (9.6) and significant survival advantage (35.5 days vs 52.5 days for cytoreductive surgery vs cytoreductive surgery + PDT, $\mathrm{p}<0.005)$. We are looking for clinical trial with new generation of PS to validate the tolerance and the effectiveness of this therapy.

PTT is a more recent therapy. Preclinical studies with gold NPs, demonstrated a regression of tumoral growth and an improvement of survival in comparison with controls (PTT mice had a survival rate of $100 \%$ during the observation period, at the contrary of others groups) with tolerable side effect. Other phase III preclinical studies could permit to validate these first effective and survival results. A lot of problematics may complicate clinical development 
(illumination technique, decision of a laser power, bowel complications, staff security) and it is not yet possible to affirm the survival benefits of these treatment.

Acknowledgements: We want to thank Dr Katrien Remaut for her contribution in reading and correcting this paper. Author contributions: All the authors have accepted responsibility for the entire content of this submitted manuscript and approved submission.

Research funding: None declared.

Employment or leadership: M. Pocard is expert consultant for GAMIDA company. M. Pocard had commercial relation with ROCHE, SANOFI, ETHICON company, Capnomed.

Honorarium: None declared.

Competing interests: The funding organization(s) played no role in the study design; in the collection, analysis, and interpretation of data; in the writing of the report; or in the decision to submit the report for publication.

\section{References}

1. Verwaal VJ, van Ruth S, de Bree E, van Sloothen GW, van Tinteren $\mathrm{H}$, Boot $\mathrm{H}$, et al. Randomized trial of cytoreduction and hyperthermic intraperitoneal chemotherapy versus systemic chemotherapy and palliative surgery in patients with peritoneal carcinomatosis of colorectal cancer. J Clin Oncol. 2003;21:373743.

2. Elias D, Lefevre JH, Chevalier J, Brouquet A, Marchal F, Classe JM, et al. Complete cytoreductive surgery plus intraperitoneal chemohyperthermia with oxaliplatin for peritoneal carcinomatosis of colorectal origin. J Clin Oncol. 2009;27:681-5.

3. Glehen O, Osinsky D, Cotte E, Kwiatkowski F, Freyer G, Isaac S, et al. Intraperitoneal chemohyperthermia using a closed abdominal procedure and cytoreductive surgery for the treatment of peritoneal carcinomatosis: morbidity and mortality analysis of 216 consecutive procedures. Ann Surg Oncol. 2003;10:863-9.

4. Simkens GA, van Oudheusden TR, Braam HJ, Luyer MD, Wieyer M), van Ranshorst B, et al. Treatment related mortality after cytoreductive surgery and HIPEC in patients with colorectal peritoneal carcinomatosis is underestimated by conventional parameters. Ann Surg Oncol. 2016;23:99-105.

5. Mirnezami R, Moran BJ, Harvey K, Cecil T, Chandrakumaran K, Carr N, et al. Cytoreductive surgery and intraperitoneal chemotherapy for colorectal peritoneal metastases. World I Gastroenterol. 2014;20:14018-32.

6. Pinto A, Eveno C, Pocard M. Update on clinical trials in colorectal cancer peritoneal metastasis. Int J Hyperthermia. 2017;33:543-7.

7. Diamond I, Granelli SG, McDonagh AF, Nielsen S, Wilson CB, Jaenicke R. Photodynamic therapy of malignant tumours. Lancet. 1972;2:1175-7.

8. Dougherty TJ, Gomer CJ, Henderson Bw, Jori G, Kessel D, Korbelik M, et al. J Natl Cancer Inst. 1998;90:889-905.
9. Azaïs H, Mordon S, Collinet P. Intraperitoneal photodynamic therapy for peritoneal metastasis of epithelial ovarian cancer. Limits and future prospects. Gynecol Obstet Fertil Senol. 2017;45:249-56.

10. Cengel KA, Glatstein E, Hahn SM. Intraperitoneal photodynamic therapy. Cancer Treat Res. 2007;134:493-514.

11. Kelly JF, Snell ME, Berenbaum MC. Photodynamic destruction of human bladder carcinoma. Br J Cancer. 1975;31: 237-44.

12. Laksmipathi T, Gould P, Johnson BE, Mackenzie LA, Frain-Bell W. Proceedings: photochemotherapy. A study of its efficacy in fifty patients suffering from psoriasis and other dermatoses. $\mathrm{Br}$ J Dermatol. 1976;95:20-1.

13. Stüttgen $\mathrm{G}$. The risk of photochemotherapy. Int J Dermatol. 1982;21:198-202.

14. Cortese DA, Kinsey JH. Hematoporphyrin-derivative phototherapy for local treatment of cancer of the tracheobronchial tree. Ann Otol Rhinol Laryngol. 1982;91:652-5.

15. Kato H, Konaka C, Ono J, Matsushima Y, Nishimiya K, Lay J, et al. Effectiveness of HPD and radiation therapy in lung cancer. Adv Exp Med Biol. 1983;160:23-39.

16. McCaughan JS, Jr, Hicks W, Laufman L, May E, Roach R. Palliation of esophageal malignancy with photoradiation therapy. Cancer. 1984;54:2905-10.

17. Tochner Z, Mitchell JB, Harrington FS, Smith P, Russo DT, Russo A. Treatment of murine intraperitoneal ovarian ascetic tumor with hematoporphyrin derivative and laser light. Cancer Res. 1985;45:2983-7.

18. De Smet L, Ceelen W, Remon JP, Vervaet C. Optimization of drug delivery systems for intraperitoneal therapy to extend the residence time of the chemotherapeutic agent. Scientific World J. 2013;25:720858.

19. Kohane DS, Tse JY, Yeo Y, Padera R, Shubina M, Langer R. Biodegradable polymeric microspheres and nanospheres for drug delivery in the peritoneum. J Biomed Mater Res A. 2006;77:351-61.

20. Bennis S, Chapey C, Couvreur P, Robert J. Enhanced cytotoxicity of doxorubicin encapsulated in polyisohexylcyanoacrylate nanospheres against multidrug-resistant tumour cells in culture. European Journal of Cancer A. 1994;30:89-93.

21. Cho KJ, Wang X, Nie SM, Chen Z, Dm S. Therapeutic nanoparticles for drug delivery in cancer. Clin Cancern Res. 2008;14: 1310-6.

22. Sadava D, Coleman A, Kane SE. Liposomal daunorubicin overcomes drug resistance in human breast, ovarian and lung carcinoma cells. J Liposome Res. 2002;12:301-9.

23. Chatterjee DK, Diagaradjane P, Krishnan S. Nanoparticlemediated hyperthermia in cancer therapy. Ther Deliv. 2011;8:1001-14.

24. Kennedy LC, Bickford LR, Lewinski NA, Coughlin AJ, Hu Y, Day ES, et al. $\underline{A}$ new area for cancer treatment: goldnanoparticles-mediated thermal therapies. Small. 2011; 7:169-83.

25. Huang X, El-Sayed IH, Qian W, El-Sayed MA. Cancer cell imaging and photothermal therapy in the near-infrared region by using gold nanorods. J Am Chem Soc. 2006;128:2115-20.

26. Dickerson EB, Dreaden EC, Huang X, El-Sayed IH, Chu H, Pushpanketh $S$, et al. Gold nanorod assisted near-infrared plasmonic photothermal therapy (PPTT) of squamous cell carcinoma in mice. Cancer Lett. 2008;269:57-66. 
27. Hirsch LR, Stafford RJ, Bankson JA, Sershen SR, Rivera B, Price RE, et al. Nanoshell-mediated near-infrared thermal therapy of tumors under magnetic resonance guidance. Proc Natl Acad Sci USA. 2003;100:13549-54.

28. Riley RS, Day ES. Gold nanoparticle-mediated photothermal therapy: applications and opportunities for multimodal cancer treatment. Wiley Interdiscip Rev Nanomed Nanobiotechnol. 2017;9:4. (epub).

29. Loo C, Lin A, Hirsch L, Lee MH, Barton J, Halas N, et al. Nanoshell-enabled photonics-based imaging and therapy of cancer. Technol Cancer Res Treat. 2004;3:33-40.

30. O'Neal DP, Hirsch LR, Halas NJ, Payne JD, West JL. Photo-thermal tumor ablation in mice using near infrared-absorbing nanoparticles. Cancer Lett. 2004;209:171-6.

31. Paciotti GF, Myer L, Weinreich D, Goia D, Pavel N, McLaughlin RE, et al. Colloidal gold: a novel nanoparticle vector for tumor directed drug delivery. Drug Deliv. 2004;11:169-83.

32. Tochner Z, Mitchell JB, Hoekstra HJ, Smith P, DeLuca AM, Barnes $M$, et al. Photodynamic therapy of the canine peritoneum: normal tissue response to[] intraperitoneal and intravenous photofrin followed by $630 \mathrm{~nm}$ light. Lasers Surg Med. 1991;11:158-64.

33. Perry RR, Smith PD, Evans S, Pass HI. Intravenous vs intraperitoneal sensitizer: implications for intraperitoneal intraperitoneal photodynamic therapy. Photochem Photobiol. 1991;53:335-40.

34. Griffin GM, Zhu T, Solonenko M, Del Piero F, Kapakin A, Busch TM, et al. Preclinical evaluation of motexafin lutetium-mediated intraperitoneal photodynamic therapy in a canine model. Clin Cancer Res. 2001;7:374-81.

35. Morlet L, Vonarx-Coinsmann V, Lenz P, Foultier MT, de Brito LX, Stewart $\mathrm{C}$, et al. Correlation between meta(tetrahydroxyphenyl) chlorin (m-THPC) biodistribution and photodynamic effects in mice. J Photochem Photobiol B. 1995;28:25-32.

36. Veenhuizen RB, Ruevekamp MC, Oppelaar H, Helmerhorst TJ, Kenemans P, Stewart FA. Foscan-mediated photodynamic therapy for a peritoneal cancer model: drug distribution and efficacy studies. Int J Cancer. 1997;73:230-5.

37. Ascencio M, Estevez JP, Delemer M, Farine MO, Collinet P, Mordon S. Comparison of continuous and fractioned illumination during hexaminolaevulinate photodynamic therapy. Photodiagnosis Photodyn Ther. 2008;5:210-6.

38. Ascencio M, Collinet P, Farine MO, Mordon S. Protoporphyrin IX fluorescence photobleaching is a useful tool to predict the response of ratovarian cancer following hexaminolevulinate photodynamic therapy. Lasers Surg Med. 2008;40:332-41.

39. Estevez JP, Ascencio M, Colin P, Farine MO, Collinet P, Mordon S. Continuous or fractionated photodynamic therapy? Comparison of three PDT schemes for ovarian peritoneal micrometastasis treatment in a rat model. Photodiagnosis Photodyn Ther. 2010;7:251-7.

40. Song K, Kong B, Li L, Yang Q, Wei Y, Qu X. Intraperitoneal photodynamic therapy for an ovarian cancer ascite model in Fischer 344 rat using hematoporphyrin monomethyl ether. Cancer Sci. 2007;98:1959-64.

41. Raue W, Kilian M, Braumann C, Atanassow V, Makareinis A, Caldenas S, et al. Multimodal approach for treatment of peritoneal surface malignancies in a tumour-bearing rat model. Int J Colorectal Dis. 2010;25:245-50.
42. Mroz P, Xia Y, Asanuma D, Konopko A, Zhiyentayev T, Huang YY, et al. Intraperitoneal photodynamic therapy mediated by a fullerene in a mouse model of abdominal dissemination of colon adenocarcinoma. Nanomedicine. 2011;7:965-74.

43. Guyon L, Farine MO, Lesage JC, Gevaert AM, Simonin S, Schmitt C, et al. Photodynamic therapy of ovarian cancer peritoneal metastasis with hexaminolevulinate: atoxicity study. Photodiagnosis Photodyn Ther. 2014;11:265-74.

44. Azaïs H, Frochot C, Grabarz A, Khodja Bach S, Colombeau L, Delhem N, et al. Specific folic-acid targeted photosensitizer. The first step toward intraperitoneal photodynamic therapy for epithelial ovarian cancer. Gynecol Obstet Fertil Senol. 2017;45:190-6.

45. Azaïs H, Schmitt C, Tardivel M, Kerdraon O, Stallivieri A, Frochot C, et al. Assessment of the specificity of a new folate-targeted photosensitizer for peritoneal metastasis of epithelial ovarian cancer to enable intraperitoneal photodynamic therapy. A Preclinical Study. Photodiagnosis Photodyn Ther. 2016;13:130-8.

46. Yokoyama Y, Shigeto T, Miura R, Kobayashi A, Mizunuma M, Yamauchi A, et al. A strategy using photodynamic therapy and clofibric acid to treat peritoneal dissemination ofovarian cancer. Asian Pac J Cancer Prev. 2016;17:775-9.

47. Sindelar WF, DeLaney TF, Tochner Z, Thomas GF, Dachoswki LJ, Smith PD, et al. Technique of photodynamic therapy for disseminated intraperitoneal malignant neoplasms. Phase I Study Arch Surg. 1991;126:318-24.

48. DeLaney TF, Sindelar WF, Tochner Z, Smith PD, Friauf WS, Thomas G, et al. Phase I study of debulking surgery and photodynamic therapy for disseminated intraperitoneal tumors. Int J Radiat Oncol Biol Phys. 1993;25:445-57.

49. Wierrani F, Fiedler D, Grin W, Henry M, Dienes E, Gharehbaghi K, et al. Clinical effect of meso-tetrahydroxyphenylchlorine based photodynamic therapy in recurrent carcinoma of the ovary: preliminary results. Br J Obstet Gynaecol. 1997;104:376-8.

50. Bauer TW, Hahn SM, Spitz FR, Kachur A, Glatstein E, Fraker DL. Preliminary report of photodynamic therapy for intraperitoneal sarcomatosis. Ann Surg Oncol. 2001;8:254-9.

51. Canter RJ, Mick R, Kesmodel SB, Raz DJ, Spitz FR, Metz JM, et al. Intraperitoneal photodynamic therapy causes a capillary-leak syndrome. Ann Surg Oncol. 2003;10:514-24.

52. Hendren SK, Hahn SM, Spitz FR, Bauer TW, Rubin SC, Zhu T, et al. Phase II trial of debulking surgery and photodynamic therapy for disseminated intraperitoneal tumors. Ann Surg Oncol. 2001;8:65-71.

53. Wilson JJ, Jones H, Burock M, Smith D, Fraker DL, Metz J, et al. Patterns of recurrence in patients treated with photodynamic therapy for intraperitoneal carcinomatosis and sarcomatosis. Int J Oncol. 2004;24:711-7.

54. Hahn SM, Fraker DL, Mick R, Metz J, Busch TM, Smith D, et al. A phase II trial of intraperitoneal photodynamic therapy for patients with peritoneal carcinomatosis and sarcomatosis. Clin Cancer Res. 2006;12:2517-25.

55. Levi-Polyachenko NH, Merkel EJ, Jones BT, Carroll DL, Stewart JH, IV. Rapid photothermal intracellular drug delivery using multiwalled carbon nanotubes. Mol Pharm. 2009;6:1092-9.

56. Takagi A, Hirose A, Nishimura T, Fukumori N, Ogata A, Ohashi N, et al. Induction of mesothelioma in p $53+/$ - mouse by intraperitoneal application of multi-wall carbon nanotube. J Toxicol Sci. 2008;33:105-16. 
57. Rittinghausen S, Hackbarth A, Creutzenberg O, Ernst H, Heinrich U, Leonhardt A, et al. The carcinogenic effect of various multi-walled carbon nanotubes (MWCNTs) after intraperitoneal injection in rats. Part Fibre Toxicol. 2014;11:59.

58. Muller J, Delos M, Panin N, Rabolli V, Huaux F, Lison D. Absence of carcinogenic response to multiwall carbon nanotubes in a 2 year bioassay in the peritoneal cavity of the rat. Toxicol Sci. 2009;110:442-8.

59. Zhang XD, Wu HY, Wu D, Wang YY, Chang JH, Zhai ZB, et al. Toxicologic effects of gold nanoparticles in vivo by different administration routes. Int J Nanomedicine. 2010;5:771-81.

60. Bagley AF, Hill S, Rogers GS, Bhatia SN. Plasmonic photothermal heating of intraperitoneal tumors through the use of an implanted near-infrared source. ACS Nano. 2013;7:8089-97.

61. Diddens-Tschoeke HC, Hüttmann G, Gruber AD, Pottier RH, Hanken $\mathrm{H}$. Localized thermal tumor destruction using dye-enhanced photothermal tumor therapy. Lasers Surg Med. 2015;47:452-61.

62. Wu CC, Yang YC, Hsu YT, Wu TC, Hung CF, Huang JT, et al. Nanoparticle-induced intraperitoneal hyperthermia and targeted photoablation in treating ovarian cancer. Oncotarget. 2015;6:26861-75.

63. Nowacki M, Wisniewski M, Werengowska-Ciecwierz K, Roszek K, Czarnecka J, takomska I, et al. Nanovehicles as a novel target strategy for hyperthermic intraperitoneal chemotherapy: a multidisciplinary study of peritoneal carcinomatosis. Oncotarget. 2015;6:22776-98.

64. Zhang Y, Liu Z, Thackray BD, Bao Z, Yin X, Shi F, et al. Intraoperative Raman-guided chemo-photothermal synergistic therapy of advanced disseminated ovarian cancers. Small. 2018;e1801022 (doi:10.1002/smll201801022).

65. Duncan R, Sat-Klopsch YN, Burger AM, Bibby MC, Fiebig HH, Sausville EA. Validation of tumour models for use in anticancer nanomedicine evaluation: the EPR effect and cathepsin B-mediated drug release rate. Cancer Chemother Pharmacol. 2013;72:417-27.

66. Maeda H. Macromolecular therapeutics in cancer treatment: the EPR effect and beyond. J Control Release.

2012;164:138-44. 